\title{
Factors Determining the Distribution and Status of the Snow Leopard Population (Panthera uncia) in Western Mongolia
}

\author{
Victor S. Lukarevskiy ${ }^{1,}$, , Munkhnast Dalannast ${ }^{2}$, Svyatoslav Lukarevskiy ${ }^{1}$, Erdenechimeg Damdin $^{3}$ \\ ${ }^{1}$ Information and Analytical Center for Support of Protected Areas, Moscow, Russia \\ ${ }^{2}$ Bat Research Center of Mongolia, Ulaanbaatar, Mongolia \\ ${ }^{3}$ Administration of Khar-Us Nuur National Park, Khovd, Mongolia
}

Email address:

vlukarevsky@mail.ru (V. S. Lukarevsky)

${ }^{*}$ Corresponding author

\section{To cite this article:}

Victor S. Lukarevskiy, Munkhnast Dalannast, Svyatoslav Lukarevskiy, Erdenechimeg Damdin. Factors Determining the Distribution and Status of the Snow Leopard Population (Panthera uncia) in Western Mongolia. Animal and Veterinary Sciences.

Vol. 7, No. 6, 2019, pp. 119-124. doi: 10.11648/j.avs.20190706.12

Received: October 25, 2019; Accepted: December 16, 2019; Published: January 17, 2020

\begin{abstract}
Studies of the distribution, assessment of the Snow leopard population, as well as the state of the populations of its main prey species, the impact of anthropogenic factors are the basis for the development of long-term and effective action plans and strategies for its conservation. To this end, we have carried out work on three different territories of the Mongolian Altai: Jargalant, Bumbat and Baatar Khairkhan Mountains. All three territories differ in the nature of the location in relation to other parts of the Snow leopard's range, and in the nature of the relief and economic use. The main method of research is the search and registration of traces of life activity of the Snow leopard and its main prey species (Mongolian marmot and Siberian ibex). For this purpose, we have passed 18 research routes with a total length of $197.5 \mathrm{~km}$ where we recorded all traces of the Snow leopard, Siberian ibex and Mongolian marmot life activities, as well as the distribution of the number of livestock. Another research method we have used is the application of camera traps. We installed 27 camera traps in total. As a result of their work we have obtained 51 photo location of the Snow leopard and identified at least 3 females, 2-3 adult males, 2-3 young individuals, the sex of which could not be established, including individuals aged about 2 years, 2 cubs. Both methods of research (search for traces of life activities and the application of camera traps) complement each other, and the correct use of camera traps can reduce the subjectivity of the results obtained by the search for traces of life activities. Thus, the reliability of the results is significantly increased. Our studies show that the largest number of traces of Snow leopard activity (the number of scrapes per $1 \mathrm{~km}$ of the route) and the largest number of photo locations were recorded in the central part of the Jargalant khairkhan mountain range - the territory that is the most remote and inaccessible for grazing livestock. In this territory, the highest frequency of Snow leopard presence was noted (20-40 scratches $/ \mathrm{km})$, and accordingly 5 from 11 identified snow leopards were registered. A similar pattern of distribution of traces of vital activity was registered for the other two territories.
\end{abstract}

Keywords: Snow Leopard, Jargalant, Bumbat, Baatar Khairkhan, Population, Photo Location, Scrapes

\section{Justification}

An international forum event devoted specifically to snow leopards (Panthera uncia) indicates the high level of interest in the state of its population at the world level, which is due to a real threat to the survival of the species. Examples from Russia [12], Kyrgyzstan [13], and Mongolia [14] show that within the surveyed territories the snow leopard population is sharply reduced everywhere. The greatest threat is the reduction in numbers and fragmentation of its natural range. The main reasons are poaching (both of snow leopards themselves and of their main prey) and the degradation of its 
habitats $[14 ; 22 ; 8 ; 21 ; 19]$. Some authors among the threats to the survival of the species indicate climate change [7].

\section{Purpose of the Research}

Identification of factors affecting the distribution and status of the snow leopard population in the specified territories of western Mongolia.

\section{Study Area}

The work was carried out in these territories of the Mongolian Altai: Jargalant, Bumbat and Baatar Khairkhan Mountains. These territories have different status. The Jargalant khairkhan mountain has the status of a national park, while the other two are open to any type of economic activity. All three sites have approximately similar physical and geographical characteristics. Livestock is grazed in all these areas, all year round.
This research was conducted from September 6 to September 25, 2013. The main material was collected on 18 research routes, a total length of $197.5 \mathrm{~km}$ (1- Jargalant khairkhan, 2 - Bumbat khairkhan, 3 - Baatar khairkhan) (Figure 1). On the routes recorded such traces of life of the snow leopard, such as scrapes, scats, urinal marks, and pugmarks. The main method of research was the search for and following of tracks used in studies of large predator mammals $[1 ; 9-12 ; 15 ; 16]$. The main provisions of the SLIMS (Snow Leopard Information Management System) method [3] are taken into account. The most reliable sign of the presence of a snow leopard is its scrapes, which all adults do, but more often the territory is marked by males. Young, non-territorial individuals do not leave scrapes. Scrapes, which are easily recognized and identified on rocks and soil, are long-lived. In this area, there are no other animals capable of leaving similar traces of vital activity, so we consider scrapes the main indicator for monitoring the state of the snow leopard population.

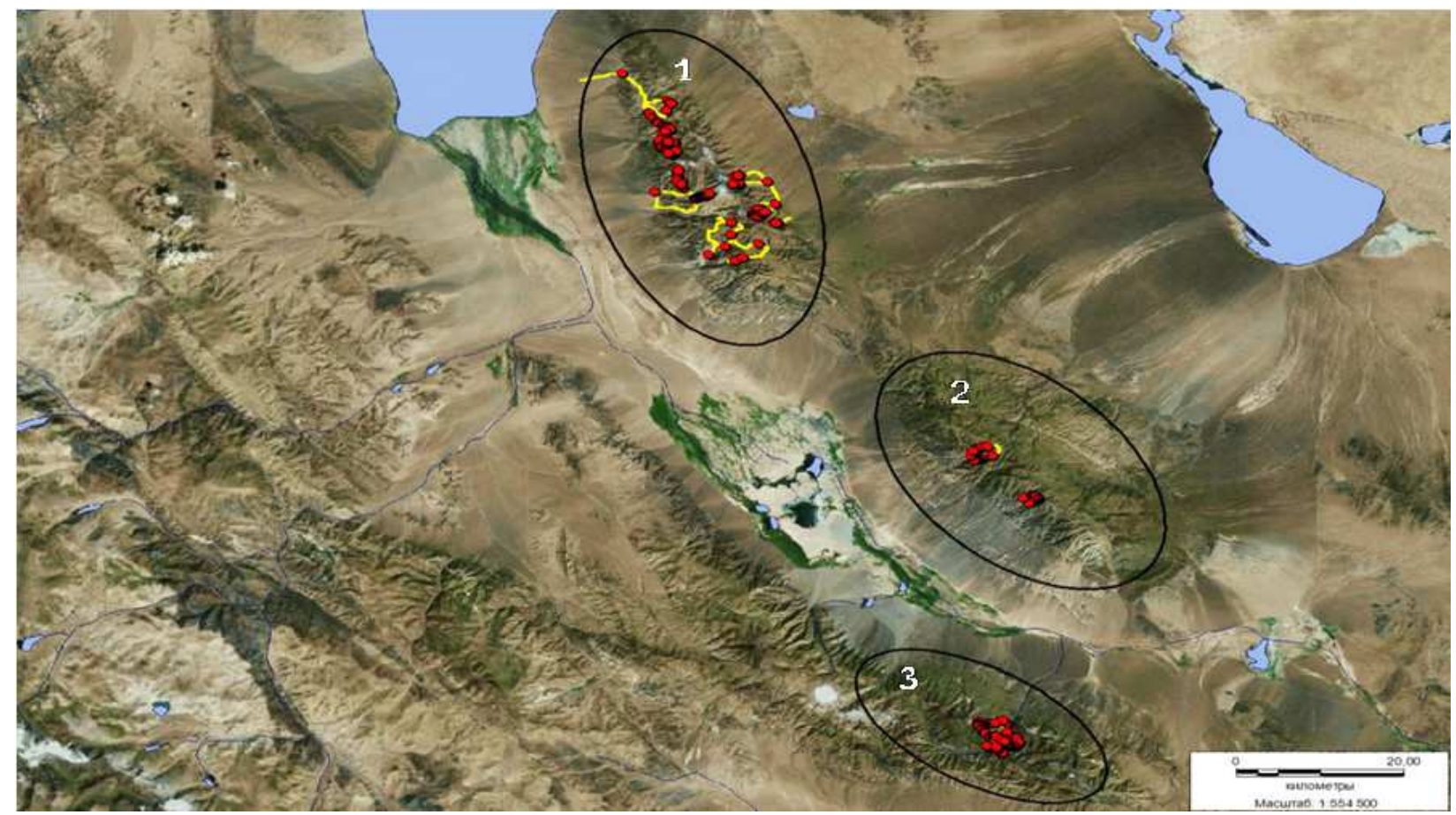

Study areas circled by black (1-Jargalant, 2-Bumbat, 3-Baatar khairkhan).

Figure 1. Study areas of snow leopard in western Mongolia.

\section{Material and Methods}

For an expert assessment of the strength and condition of the groups within the sample population, we considered the following criteria: intensity of marking the territory with scrapes; the character of scrapes (single or presence of clusters), frequency of updates of scrapes, and site visit(s).

In the territory of Jargalant khairkhan, a network of 27 camera traps (Bushnell) was installed (Figure 2). Traps were installed in places where the likelihood of visits by snow leopards was maximum, namely in places with the greatest marking activity. Snow leopards, like other large cats, use features of relief for moving and directing its movement [10; $12 ; 20]$. Therefore, we considered this when choosing places for the installation of photo traps. The most probable routes of snow leopards pass along the edges of plateau ridges, or on blade-like ridges and spurs. The use of photo traps to account for large cats is detailed in the works of Karant [4]. Detailed work on the study of the snow leopard using photo traps in Mongolia was carried out by McCarthy [18], Augugliaro [2] and others. Since patterns of color of snow leopards are individual and asymmetric on the sides, cameras of each trap were located opposite each other, so that both 
sides of the animal could be photographed simultaneously [4; 5]. The location of the photo traps was recorded using GPS. However, due to technical failures of photo traps, much of the data could not be used for analysis utilizing modeling processes (when working in the CAPTURE program) [6].
Nevertheless, obtained results do allow use of these data when comparing materials obtained by other methods (i.e., search and tracing). Of the 27 photo traps, 12 photo traps were found to be faulty for various technical reasons. A total of 51 photo locations of snow leopards were verified.

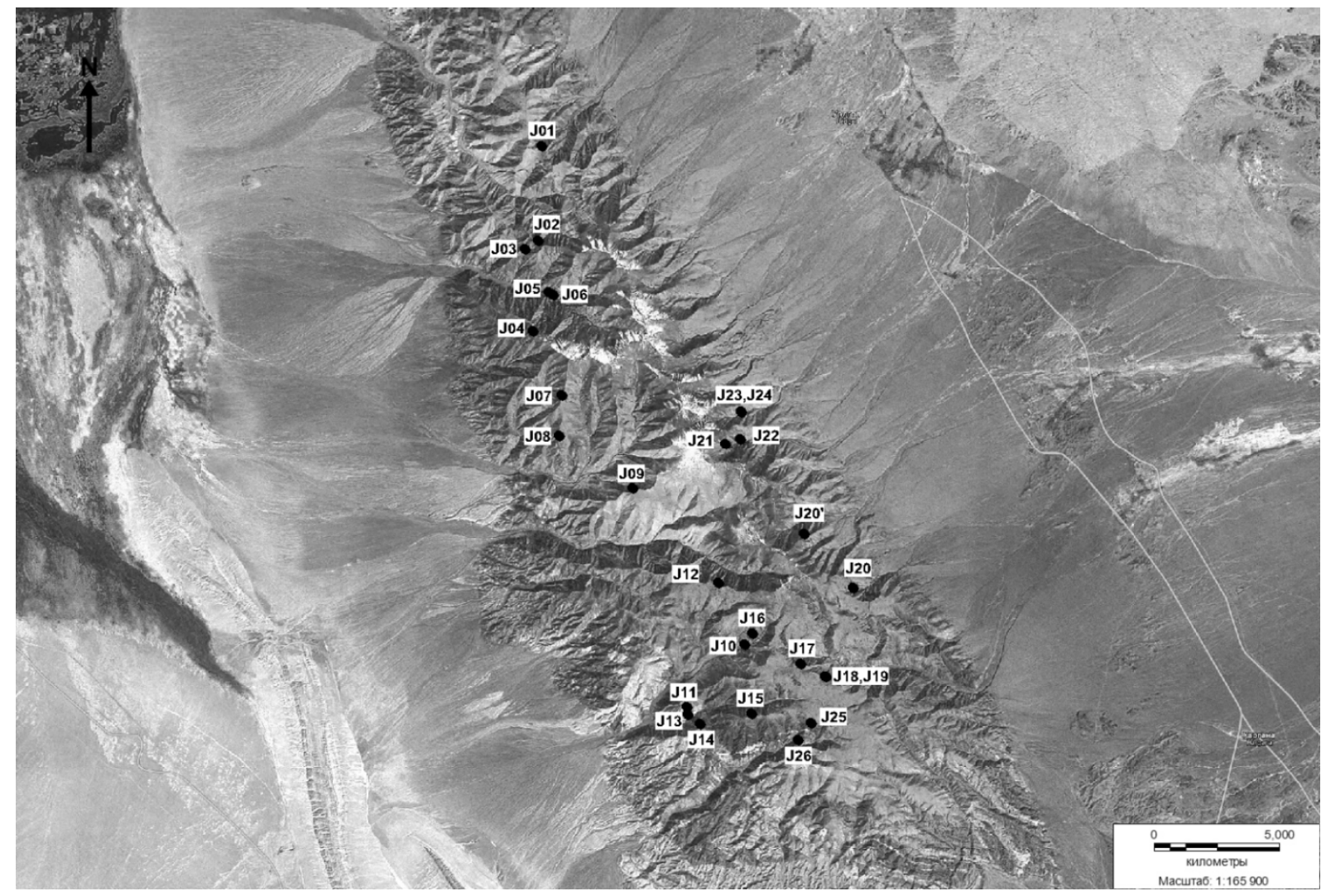

Figure 2. Camera trap locations in the Jargalant khairkhan Mountain.

\section{Results and Discussion.}

According to the collected data, the snow leopard is widespread almost everywhere in the middle and upper mountain belt at an altitude of 1800-2000 to $3800 \mathrm{~m}$. The distribution of the snow leopard depends entirely on the distribution of the main types of its prey. In most of the areas studied, the main object of snow leopard nutrition in the summer season is marmot $(n=33$, more than $50 \%$ of meetings) (Figure 3). Because of factors disturbing or interrupting hunts, snow leopards follow the Siberian ibex to the upper belt of the mountains, in places with a heavily dissected relief that is inaccessible for grazing. The results of taking into account the traces of life of the snow leopard show that the greatest density is recorded on Jargalant khairkhan. In its central part of transects, according to the SLIMS method (Jackson, Hunter, 1996) (the transect is a section of the route with the same relief along the crest of a ridge or along a river valley), the highest density of marking characteristics--from 21 to 44 scrapes/km-- was recorded, the largest number of clusters and the largest number of photos of snow leopards (Figure 4). Thus, the marking activity of snow leopards in a given area is significant, even when compared with other data in Mongolia [17]. The greatest number of photo locations also falls on the inner part of the mountain massif. On three registrations more than $50 \%$ of all locations belonging to five different snow leopards were registered, which explains the increased marking activity there. The photo traps were placed relatively evenly throughout the territory.

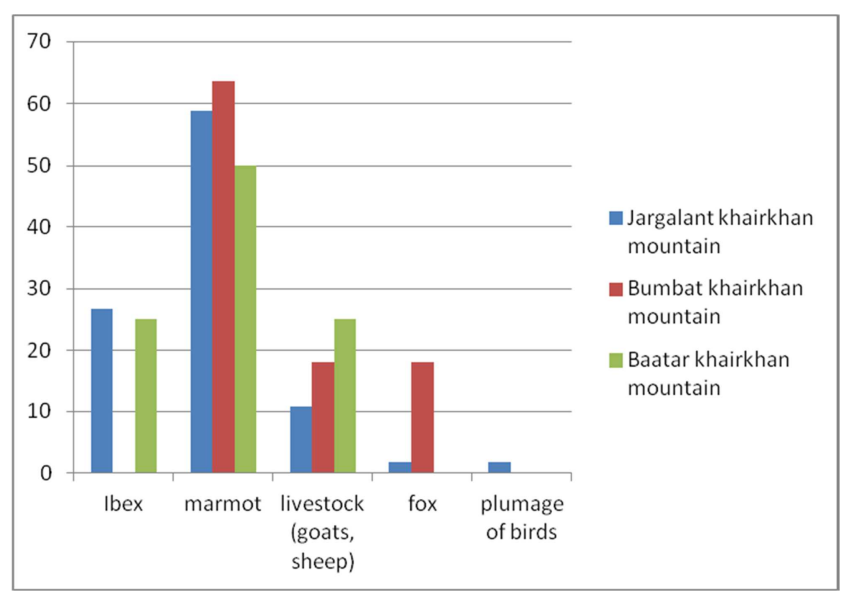

Figure 3. Occurrence of animal remains in snow leopard feces. 


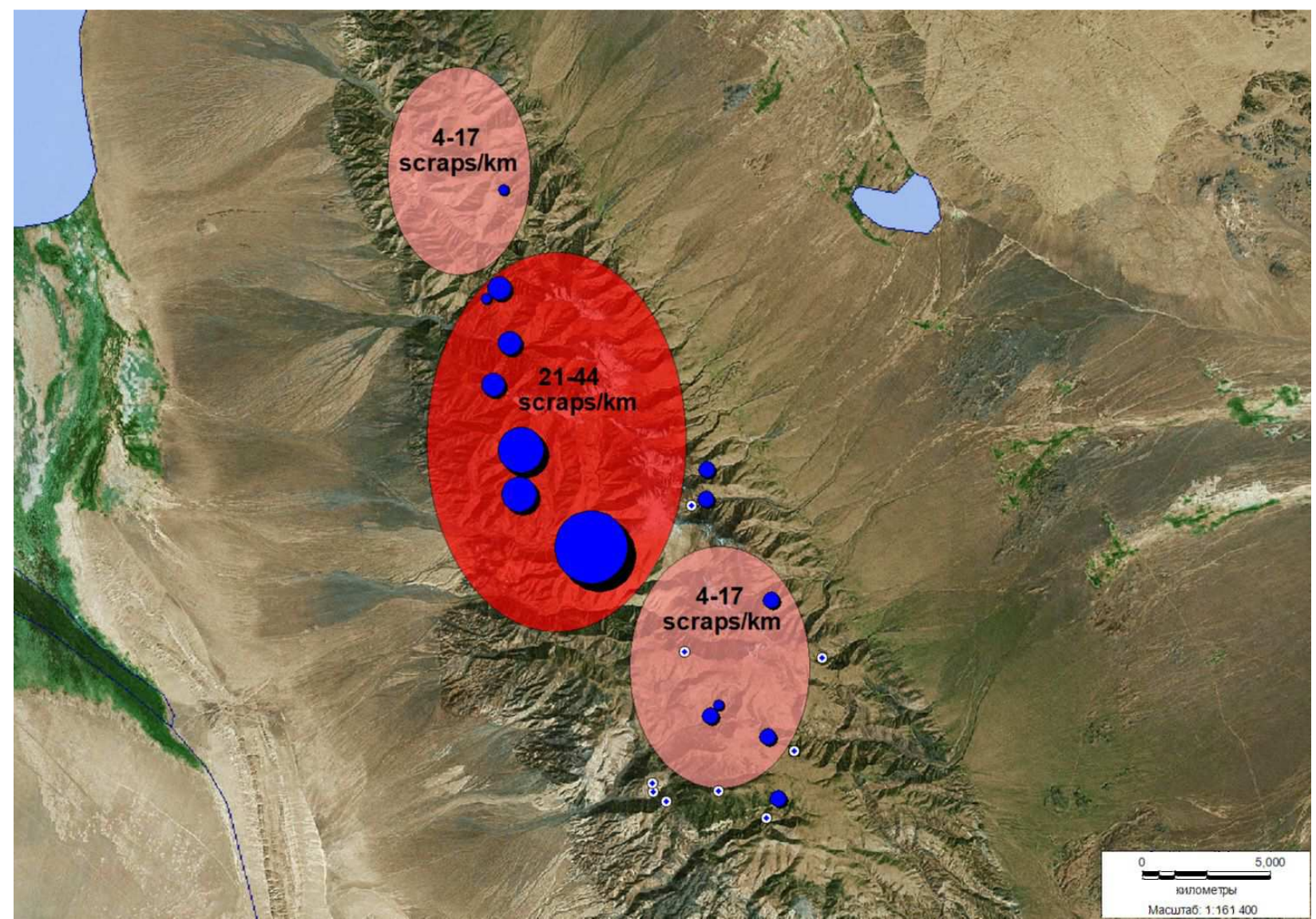

Figure 4. The distribution and abundance of the snow leopard depends on the size of the territory, the nature of the terrain, its accessibility to humans and the status of populations of the main prey species.

It should be noted that at the time of our research there were no livestock on the ranges of Bumbat and Baatar khairkhan mountains. These pastures are used in winter and summer, while on the ridge of Jargalant khairkhan, livestock is grazed in different sections all year round.

Depending on the density of the population, which directly effects the intensity of marking of the territory on the routes we recorded, clusters of scrapes (clusters) appear due to the re-marking of traces by relatives. As a rule, such clusters appear in places visited by snow leopards within an interval of 3-5 days. According to expert estimates, this group includes at least 3-4 adult females, 3-5 adult males and about 4-5 non-territorial individuals--a total of about 10-12 snow leopards. According to the data of photo recorders for the period of September 2013 to December 2013, no less than three females, 2-3 adult males and 2-3 young, 2 kittens/one-year-olds were identified. For some reason, the female tagged here earlier with a satellite collar on photo traps was not marked during this period.

Most of the Bumbat khairkhan ridge is accessible to horseback riding, so the Siberian ibex is extremely rare here (on two routes we met only single traces of Siberian ibex presence), which makes this ridge much less suitable as a habitat for snow leopards. The marking activity of snow leopards on Bumbat khairkhan ridge is 3-4 times less than on Jargalant ridge. Our routes on Bumbat khairkhan ridge, as well as the route in the Jargalant khairkhan Mountains, passed through the most inaccessible areas in the upper part of the mountains. In the mountains of Bumbat khairkhan, with rare exceptions, we did not register clusters of scrapes, which indicates a disturbed structure of the snow leopard population in this area. Due to the almost complete absence here of the Siberian ibex and other wild ungulates, the possibility of survival of snow leopard kittens becomes questionable, as large-scale prey are needed to feed them, which is not present throughout the summer. Our findings were confirmed later in December, when the kitten of the thirties was forced to look for food at a shepherds' camp (http://www.ugluu.mn/46507.html/). Therefore, we estimate the size of this grouping to be about 3-4 individuals.

The Baatar khairkhan Mountain Range is considerably larger than the ridges of Jargalant and Bumbat khairkhan. The structure of the relief is similar to the Jargalant Mountain Range, and many parts of the mountains are accessible to humans only on foot, so the Siberian ibex is quite common on most of these mountains. There are groups of 20-30 individuals. Accordingly, the occurrence of snow leopard tracks is much higher than on the Bumbat khairkhan Ridge, but somewhat lower than on the Jargalant khairkhan Ridge. We cannot give exact estimates of the numbers of snow leopards here, as only a small part of this ridge has been surveyed. If we assume that the distribution of the snow 
leopard is relatively uniform throughout the range, or forms concentrations in the region of the most inaccessible areas, then we can estimate this grouping also at 10-12 individuals.

It should be noted that the Jargalant khairkhan Ridge is a relatively isolated mountain knot, which has a small isthmus with the Bumbat khairkhan Ridge, while the Baatar khairkhan Range is one of the spurs of the main Altai Mountain Range. The grouping of snow leopards on the Jargalant mountain ange is isolated by a wide desert and semi-desert valley, used by cattle ranchers throughout the year. Thus, this grouping is of great scientific and environmental interest, in terms of survival of small populations.

\section{Conclusions}

Our research shows that in the conditions of increasing anthropogenic pressure, increasing the number of livestock for the preservation of the snow leopard, the most important are the size and shape of the terrain of the mountain range, its availability as a pasture for livestock, as well as for people. That is why the greatest frequency of marking of the territory is registered, on the routes passing through the central part of the mountain range, where wild ungulates find the best protective habitat.

1. The highest frequency of marking territory is found on the routes passing through the central part of the ridge.

2. The main factors determining the location of snow leopard are the placement of Siberian ibex and the factor of disturbance.

3. The relatively high marking activity of snow leopards in the study region indicates a relatively high population density.

4. The population of snow leopards in the mountains of Bumbat khairkhan can be mantained only by the preservation of existing migration from the Jargalant khairkhan Mountain Range.

5. Analysis of the nutrition of the snow leopard shows that one of the main objects of its nutrition is domestic animals, which causes the main threat to its conservation.

\section{Acknowledgements}

We express our sincere gratitude to all WWF Mongolia colleagues for the opportunity to visit the western part of Mongolia and to collect material on the biology of the snow leopard, as well as to all rangers of the Administration of KharUs Nuur National Park, for their hospitality and cooperation in our work. We especially want to express our gratitude to the drivers and guides N. Chimed-Ochir and Sh. Gantulga, who provided great support in the field. The authors thank Eleanor Pate for editing the English version of the manuscript.

\section{References}

[1] Ahlborn G. G., Jackson R. M., Marking in free-ranging snow leopards in Western Nepal: 1988. Preliminary assessment//Proceedings of the Fifth International Snow Leopard Symposium. P. 25-51.
[2] Augugliaro C, Paniccia C, Janchivlamdan C, Monti IE, Boldbaatar T, Munkhtsog B (2019) Mammal inventory in the Mongolian Gobi, with the southeasternmost documented record of the Snow Leopard, Panthera uncia (Schreber, 1775) in the country. Check List 15 (4): 565- 578. https://doi.org/10.15560/15.4.565

[3] Jackson R. M., Hunter D. O., Snow Leopard Survey and Conservation Handbook. International Snow Leopard Trust. Seattle, 1996. Second Edition. 189 pp.

[4] Karanth K. U. Estimating tiger populations from camera-trap data using capture-recapture models// Biol. Conserv. 1995. Vol. 333-338.

[5] Karanth K. U. and Nichols J. D. Estimation of tiger densities in India using photographic capture and recapturess. Ecology 79. 1998. Pp.: 2852-2862.

[6] Karanth K. U., Kumar N. S. and Nichols J. D. Field surveys: Statistical concepts: estimating absolute densities of tigers using capture-recapture sampling. In Monitoring tigers and their prey. Center Wildlife Studies, India. 2002. P. 139-150.

[7] Kazmi F. A. Ecological impacts of climate change on snow leopard (Panthera uncia) in South Asia. Preprint - August 2019. https://www.researchgate.net/publication/335523911

[8] Li J., Lu Z. Snow leopard poaching and trade in China 20002013. Biological Conservation 176 (2014) 207-211. www.elsevier.com/locate/biocon

[9] Lukarevskiy V. S. Leopard (Panthera pardus) na Zapadnom Kopetdage: razmeshcheniye, chislennost', osobennosti ekologii i povedeniya//Zool. zhurn. 1993. T. 72. Vyp. 1. S. 131-141. (In rus.)

[10] Lukarevskiy V. S. Leopard, polosataya giyena i volk v Turkmenistane. M., «Signar» 2001. 128 s. (in rus.)

[11] Lukarevskiy V. S. Kommunikativnoye povedeniye leoparda (Panthera pardus) v Tsentral'noy Azii i na Kavkaze//Povedeniye i povedencheskaya ekologiya mlekopitayushchikh. Mat-ly nauchnoy konferentsii (4-8 oktyabrya 2005 g., Chernogolovka). M., 2005. S. 191-194. (In rus.)

[12] Lukarevskiy V. S., Poyarkov A. D. Sovremennoye sostoyaniye populyatsii irbisa (Uncia uncia, Carnivora) v Rossii//Zool. zhurn. 2008. T. 87, № 1. Str. 114-121. (in rus.)

[13] Lukarevskiy V. S., Umetdbekov A. O sostoyanii nekotorykh gruppirovok irbisa v Kyrgyzstane. Zhurnal Selevinia, 2011, str. $162-167$. (In rus.)

[14] Lukarevskiy V. S., Purevsuren S. Sostoyaniye gruppirovok irbisa Uncia uncia na okhranyayemykh territoriyakh severo-zapadnoy Mongolii. Zhurnal Selevinia, 2011, str. 167-174. (in rus.)

[15] Lukarevskiy V., Askerov E., Hazaryan Gr. Condition of the Leopard Population in the Caucasus. Beitrage zur Jagd \& Wildforshung, Bd. 29. 2004. PP. 303-319.

[16] Matyushkin Ye. N., Koshkarev Ye. P. Sledy snezhnogo barsa//Okhota i okhotn. khoz-vo. 1990. № 2. S. 14-17. (In rus.)

[17] McCarthy, T. M., Ecology and conservation of snow leopards, Gobi bears, and wild Bactrian camels in Mongolia. Ph.D. Dissertation, University of Massachusetts Amherst, MA, 2000. p. 133. 
[18] McCarthy T., Murray K., Sharma K., ORJAN Johansson O., Preliminary results of a long-term study of snow leopards in South Gobi, Mongolia. Cat News 53, 15-19.

[19] Maheshwari A, Niraj S. K. Monitoring illegal trade in snow leopards: 2003-2014. Global Ecology and Conservation 14 (2018). http://www.elsevier.com/locate/gecco

[20] Schaller G., Crawshaw P. G. (Jr.), Movement patterns of Jaguar. Biotropica, vol. 12, 1980. N 3, p. 161-168.
[21] Watts S. M, McCarthy T. M, Namgail T (2019) Modelling potential habitat for snow leopards (Panthera uncia) in Ladakh, India. PLoS ONE 14 (1): e0211509. https://doi.org/10.1371/journal.pone.0211509

[22] White K. D. The Snow Leopard and Cultural Landscape in Contemporary Kazakhstan. Society \& Animals 26 (2018) 123. 